might have driven a faster recovery. Estimates of weathering rates from more recent interglacial-glacial cycles suggest that weathering rates can, counter-intuitively, be higher in cold climates, under special conditions ${ }^{5}$. Perhaps the PETM was also a special case for the weathering feedback.

Alternatively, Bowen and Zachos propose that the uptake of carbon by the biosphere speeded the recovery. On geologic timescales, geochemists have been conditioned to look away from organic carbon as a stabilizer of atmospheric $\mathrm{CO}_{2}$ concentrations, because the organic carbon cycle is also charged with maintaining the atmospheric oxygen concentration. An imbalance of the oxidative weathering of organic carbon relative to its burial in sediments could double atmospheric oxygen, or deplete it, in a few million years. However, the amount of carbon we're talking about - a few thousand gigatonnes - could easily be mopped up by organic carbon with minimal effects on oxygen levels, just as atmospheric oxygen is only very slightly affected by fossil fuel combustion today.
The harder aspect to explain may be the plateau itself. During the plateau, the carbon cycle seems to be resisting a return to its previous equilibrium. We know that carbon flushes through the surface carbon cycle continuously: it is released from the solid Earth in volcanic gases and deep-sea hot-spring fluids, and eventually returns as carbonates. Therefore, the presence of a plateau seems to suggest an ongoing release of light carbon after the initial pulse. But it would need to be just enough to counteract the flushing of the carbon from the atmosphere.

The simplest way to reach such a plateau is a continuous release of carbon at a uniform rate, although this would tend to pull the ${ }^{13} \mathrm{C}$ down slowly, on a timescale of about 100,000 years ${ }^{6}$. Adding ${ }^{12} \mathrm{C}$ from the system more quickly than that - in accordance with the new chronology - and then staying at that steady value for 100,000 years would take a delicate balancing act. Perhaps some organic reservoir was released abruptly, continued degassing slowly for 100,000 years - by coincidence, just enough to replenish the loss of light carbon - and then just as abruptly reformed again.

Unfortunately, it is really hard to determine the timings of events so far in the past $^{7}$. Bowen and Zachos ${ }^{1}$ have not written the last word on the timing and duration of the PETM, but they have shown that it will be very revealing, and perhaps relevant to our own distant future, to get this nailed down solidly.

David Archer is in the Department of the Geophysical Sciences, University of Chicago, Chicago, Illinois 60637, USA.

e-mail:d-archer@uchicago.edu

\section{References}

1. Bowen, G. \& Zachos, J. Nature Geosci. 3, 866-869 (2010).

2. Zachos, J. C. et al. Science 292, 686-693 (2001).

3. Berner, R. A. \& Kothavala, Z. Am. J. Sci. 301, 182-204 (2001).

4. Stanley, S. M., Ries, J. B. \& Hardie, L. A. Proc. Natl Acad. Sci. USA 99, 15323-15326 (2002)

5. Munhoven, G. Global Planet. Change 33, 155-176 (2002).

6. Kump, L. R. \& Arthur, M. A. Chem. Geol. 161, 181-198 (1999).

7. Lourens, L. J. et al. Nature 435, 1083-1087 (2005).

Published online: 21 November 2010

\title{
MARINE GEOLOGY
}

\section{Release through erosion}

Methane is continually produced by microbes that decompose organic matter in sediments at the bottom of the sea. And thermal decomposition of organic matter buried deep beneath the ocean causes methane to seep up from depth. Both methane sources can become trapped in subsurface reservoirs, either as gas or locked into gas hydrate - if the pressure and temperature are just right. Today, huge reservoirs of methane are found, mainly along continental margins. However, slight changes in temperature or pressure have the potential to destabilize the reservoirs, either slowly through venting or catastrophically through seafloor failure. In the latter case, large amounts of methane could enter the oceans and - unless the gas is oxidized quickly - the atmosphere.

Catastrophic destabilization may have occurred about 50,000 years ago offshore from Japan, near the Nankai trough. Nathan Bangs and colleagues at the University of Texas imaged the sea bed and subsurface using three-dimensional seismic data and cores of sediment drilled from the ocean bottom (Geology 28, 1019-1022; 2010). The images reveal a

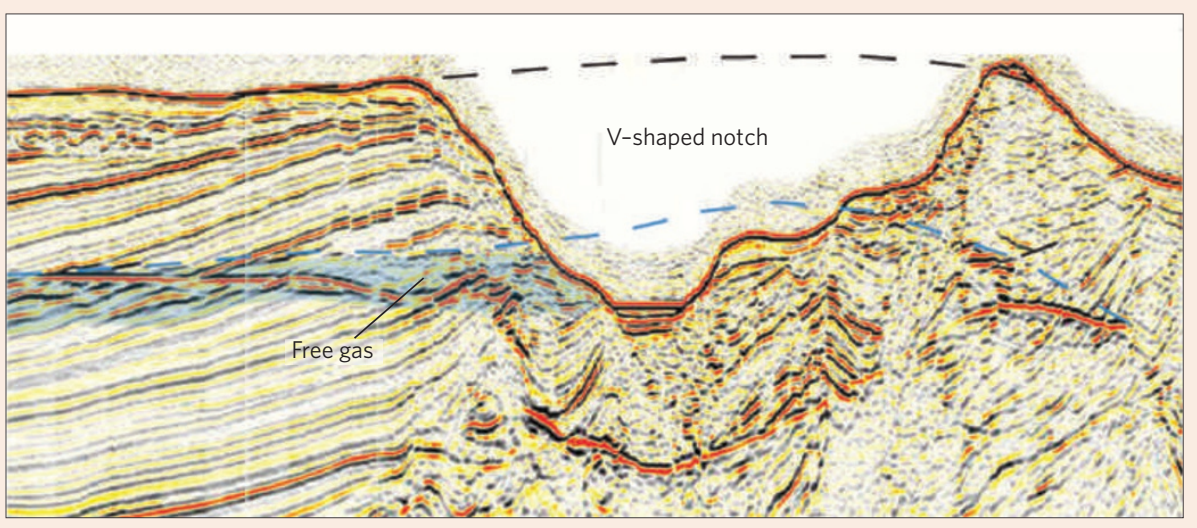

large, sharp-edged, $V$-shaped notch that cuts $400 \mathrm{~m}$ through the ocean floor, down into hydrate-laden sediments.

In the same region, there are signs that strong currents at the bottom of the ocean could have eroded away tens of metres of sea floor. Taking this observation together with the evidence for hydrate destabilization, the researchers hypothesize that erosion of the sediments above a methane reservoir may have unroofed over-pressured gas and hydrate-laden sediments, and sparked a positive feedback loop.
Based on the volume of eroded material and the concentration of hydrates in the sediments, the eroded notch alone could have released $1.51 \times 10^{11} \mathrm{~m}^{3}$ of methane, approximately $3 \%$ of the quantity found in the atmosphere at present.

Bottom currents strong enough to erode seafloor sediments are not uncommon. More surprises from the bottom of the ocean may therefore be in store.

AMY WHITCHURCH 